Original Research Paper

\title{
Estimated Greenhouse Gases Emissions from Mobile and Stationary Sources in the Limestone and Basalt Rock Mining in Thailand
}

\author{
${ }^{1}$ Dubsok Atima and ${ }^{2}$ Kittipongvises Suthirat \\ ${ }^{1}$ Inter-Department of Environmental Science Graduate School, \\ Chulalongkorn University, Bangkok, Thailand \\ ${ }^{2}$ Environmental Research Institute, Chulalongkorn University (ERIC), \\ Research Program of Toxic Substance Management in the Mining Industry, \\ Center of Excellence on Hazardous Substance Management (HSM), \\ Research Unit of Site Remediation on Metals Management from Industry and Mining (Site Rem), \\ Chulalongkorn University, Bangkok, Thailand
}

Article history

Received: 12-09-2016

Revised: 21-10-2016

Accepted: 24-10-2016

Corresponding Author: Kittipongvises Suthirat Environmental Research Institute, Chulalongkorn University (ERIC), Bangkok 10330, Thailand

Email: suthirat.k@chula.ac.th

\begin{abstract}
Mineral processing can become more environmentally sustainable by integrating practices that reduce all environmental impact of mining operations. Along with pollution problems, global climate change is presently one of the most important environment concerns. This research aimed to identify all potential sources and also compare the net emissions of greenhouse gases (GHGs) from the limestone and basalt rock mining operations in Thailand. Limestone (Plant I) and basalt (Plant II) rock mining located in the central and the northeast of Thailand were selected as research case studies. The results indicated that the total amount of GHGs emitted from limestone mining operation were approximately $1,457.61$ and $1,753.73$ $\mathrm{tCO}_{2}$-eq in 2014 and 2015, respectively. Estimated GHGs intensity ranged between 18.83 to $22.36 \mathrm{kgCO}_{2}$-eq/tonne of rock product. Similarly, over 2014 to 2015 , the range of total GHGs emissions from basalt rock mining was about $1,467.27$ to $1,670.18 \mathrm{tCO}_{2}$-eq. Interestingly, estimated GHGs intensity of basalt mining was roughly two times greater than limestone rock mining (31.85 to $35.72 \mathrm{kgCO}_{2}$-eq/tonne of product). By scope, direct emission from transport-related activities in both limestone and basalt rock mining was by far the largest source of emissions (45-62\%) compared to indirect emission from purchased grid-electricity (34-40\%). Some GHGs mitigation options and also challenges ahead for archiving environmental sustainability in the mining industry in Thailand were further raised.
\end{abstract}

Keywords: Basalt Mining Greenhouses Gases Emissions, Industrial RockConstruction, Limestone Mining, Thailand

\section{Introduction}

Climate change is considered to be one of the most profound global problems of our time. Many lines of scientific evidence show that the earth's climate is continually changing. For instance, global average temperature increased of around $0.76^{\circ} \mathrm{C}$ over 1905 to 2010, global sea level rose at an average rate of $0.17 \mathrm{~cm}$ per year over 1900 to 2010 , and the thickness of the Antarctic ice sheet significantly decreased by $40 \%$ over 1960 to 2010 (Intergovernmental Panel on Climate Change: IPCC, 2013). Many scholars agree that a changing climate is largely caused by the accumulation of green house gases (GHGs) in the atmosphere as a result of human activities (i.e. fossil fuel burning). Evidently, the global concentration of carbon dioxide $\left(\mathrm{CO}_{2}\right)$ has increased from a pre-industrial value of 280 parts per million (ppm) to $395 \mathrm{ppm}$ in 2012. Globally, energy sector has the highest GHGs emissions (31\%) compared to transport (27\%) and industrial sector (21\%) (United State Environmental Protection Agency: US EPA, 2014).

\section{Thailand's GHG Emissions}

Similarly, in Thailand, the Office of Natural Resources and Environment Policy and Planning reported that energy sector is responsible for 
approximately $70 \%$ of total GHGs emissions in 2000 , followed by agricultural and industrial sector with $22.60 \%$ and $7.20 \%$, respectively (Office of Natural Resources and Environmental Policy and Planning: ONEP, 2011). Although industry remains in the third rank of GHGs emissions, however, it plays a critical role in any thriving national economy. In 2011, the contribution of industrial sector to the national Gross Domestic Product (GDP) was about 34\%. Among these, mining contributed about $5 \%$ of the total GDP (Office of the National Economic and Social Development Board: NESDB, 2015). Limestone has the largest share of the total production, followed by lignite and basalt. Most of mined products are commonly used as an industrial rockconstruction (Fig. 1) (DPIM, 2016).

While mining is an important economic activity, increasing demand for mineral resources has gained momentum in recent times due to growing concerns over sustainability issues (i.e. technology, economics, social and environmental dimensions) (Dubiński, 2013). There has also been renewed international debate and attention on the sustainability of mining, due to strong public sentiment on social and environmental problems surrounding the mining industry. Because there is no doubt in fact that processing of mineral resources may lead to various environmental problems such as pollution, energy and resources depletion and also GHGs emissions to the atmosphere. All of these aspects are referred to as resource intensity. It is vitally important to link long-term trends in mining and mineral production to key environmental aspects such as energy and water consumption, chemical inputs, solid waste management, GHGs emissions and other pollutants (Mudd, 2010). For example, to combat climate change and its impacts (SDG 13 on climate change: UN, 2014), mining industry can contribute to a solution by engaging in dialogue with key stakeholders to enhance adaptive capacity to climate risks and by reducing their carbon footprint. Mudd (2007) and Mudd and Diesendorf (2008), for instance, investigated all information on energy, water and greenhouse gases costs per unit mineral production with respect to ore throughput. Overall, the relationship between the above resource intensity and production can also be used in the sustainability debate which surrounds mining industry, including forecasting studies or scenario development processes (Mudd, 2010).

\section{Thailand's Green Mining Policy}

The Royal Thai Government has launched the "Green Mining Policy" since 2009. Under this scheme, the policy aims to encourage mining entrepreneurs to go 'green'. Following are the six major principles (Niyomthai and Wattanawan, 2014):

- Environmental and social responsibility

- Pollution prevention and reduction of the negative environmental impacts

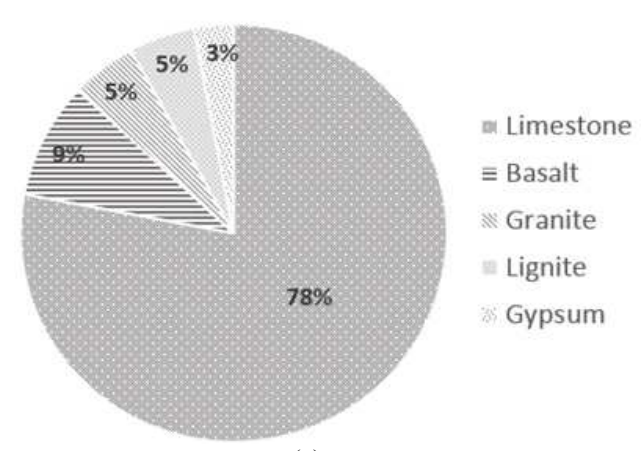

(a)

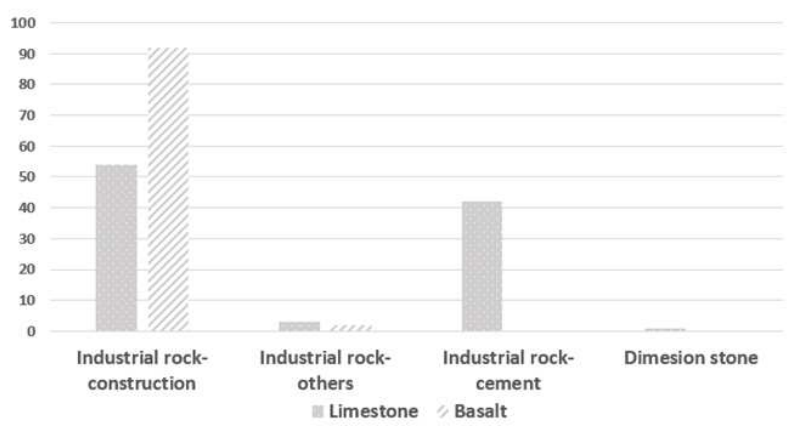

(b)

Fig. 1. Share of mineral resources production (a); limestone and basalt utilization in Thailand in 2013 (b) (modified from the Department of Primary Industries and Mines: DPIM, 2016)

- Keeping all stakeholders safe and healthy during mining operations

- Operating areas are clean and green

- Transparency and accountability

- Enhancing efficient use of mineral resources with the aim of achieving sustainable development in the mining industry

\section{Materials and Methods}

\section{Case Studies Selection}

Geographically, potential mineral resource locations and active quarries are located in various regions in Thailand. As such, the locations of limestone are mainly in the central region. Whereas, basalt resources are in the eastern and north-eastern part (DPIM, 2016). Therefore, both limestone and basalt rock quarrying operations in the central (Plant I) and the north-eastern (Plant II) region of Thailand were selected as research cases (Fig. 2).

\section{Estimation of GHGs Emissions}

In this research, GHG emissions were assessed in accordance with the GHG Protocol: A corporate accounting standard issued by the World Resource Intuition (WRI) and the World Business Council for Sustainable Development (WBCSD) (WRI, 2011). 
Table 1. Scope of GHGs emissions

Scope 1: Direct GHGs emissions refer to all emissions from owned or controlled sources (operational control) by the organization. This source of emission is considered mandatory by the GHGs protocol.

Scope 2: Indirect GHGs emission refer to emission derived from the purchase of electricity that indirectly generated by the organization. This scope is also considered mandatory by the Protocol.

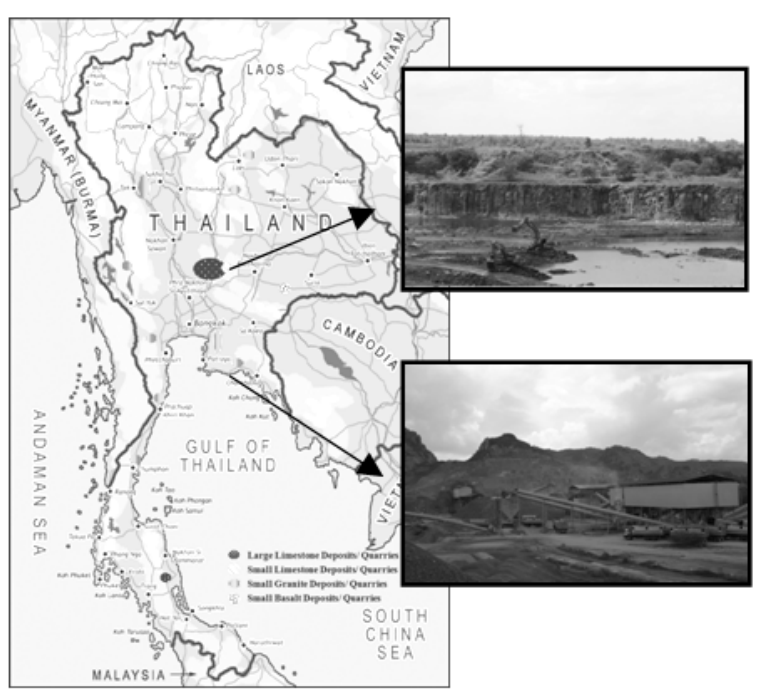

Fig. 2. Map of Thailand's rock deposits (modified from Tangchawal, 2005) and research cases (limestone mining: Plant I and basalt mining: Plant II)

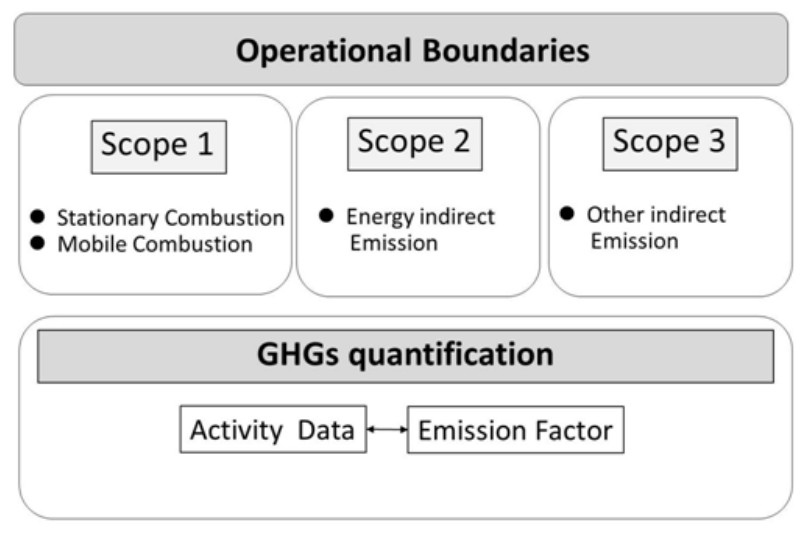

Fig. 3. Method of measuring GHGs emissions (WRI, 2011)

The key steps in estimating the net GHGs emission were briefly shown in Fig. 3.

\section{Defining the Operational Boundaries}

The operational boundaries included all direct and indirect emissions associated with the limestone and basalt rock mining. As shown in Table 1, the potential sources of GHGs emission were systematically investigated.
Table 2. Operational boundaries and scope of GHGs emissions

\begin{tabular}{llll}
\hline Scope of emission & Activity & Data source & Unit \\
\hline $\begin{array}{l}\text { Direct emissions } \\
\text { (Scope 1): Mobile } \\
\text { combustion source }\end{array}$ & $\begin{array}{l}\text { Diesel fuel } \\
\text { consumption }\end{array}$ & - Fuel bills & - Interviews \\
$\begin{array}{l}\text { Direct emissions } \\
\text { (Scope 1): }\end{array}$ & $\begin{array}{l}\text { Blasting agent } \\
\text { consumption }\end{array}$ & $\begin{array}{l}\text { - Blasting permit } \\
\text { Non-combustion }\end{array}$ & $\mathrm{Kg}$ \\
$\begin{array}{l}\text { activities } \\
\text { Indirect emission }\end{array}$ & $\begin{array}{l}\text { Electricity } \\
\text { consumption for } \\
\text { comminution (i.e. } \\
\text { crushing and grinding) }\end{array}$ & - Interviews & \\
(Scope 2) & & & $\mathrm{kWh}$ \\
\hline
\end{tabular}

Only scope 1 and 2 were accounted as the potential sources of GHGs emissions in this study. As a voluntary approach, scope 3 (i.e. indirect sources such as the emissions of waste management, transportation of employees, etc.) was excluded. In terms of the operational boundaries of the case studies, Table 2 illustrates all potential sources of emissions of both Plant I and Plant II.

\section{Estimation of GHGs Emissions}

According to the GHGs protocol, as shown in Eq.1, GHGs emissions from both direct and indirect sources can be done as follows:

GHGs emissions $=$ Activity Data $\times$ Emission factor $(\mathrm{EF})$

where, Activity data is all information used to calculate GHGs emissions from the mining processes such as quantity of diesel fuel consumed, electricity consumed, and also amount of blasting agent used.

Emission Factor (EF) is defined as an average emission rate of a given GHGs for given sources, relative to unites of activity.

As above mentioned, Gao et al. (2013) observed that the estimation of emissions based on activity data multiplied by GHG emission factors is widely used and recommended. In this study, EF values issued by TGO and US EPA were used in Equation 1. For instance, EF of diesel fuel is $2.7446 \mathrm{kgCO}_{2}$-eq/L (TGO, 2015), EF of blasting agent (ammonium nitrate/ fuel oil: ANFO) is $2.390432 \mathrm{kgCO}_{2}$-eq $/ \mathrm{kgANFO}$ (US EPA, 1995) and EF of grid-electricity is $0.5813 \mathrm{kgCO}_{2}$-eq/kWh (TGO, 2012). The GHGs emissions of the electric-powered equipment were calculated by applying the amount of power consumption and the EF of grid-electricity. Within this, based on 2 year-average (2014-2015), the estimation of net GHGs were expressed in the unit of " $\mathrm{tCO}_{2}$-eq" (tonne carbon dioxide equivalent). Additionally, the emission intensity is a measure of the amount of GHGs emitted per unit of electric power consumed in the unit of $\mathrm{kgCO}_{2}$-eq per tonne product. Equation 2 was used to estimate emission intensity in this study, as follows:

Emission intensity $=$ GHGs emission/Production

where, Emission intensity is the level of GHGs emissions per unit of production. 


\section{Results and Discussion}

\section{Net GHGs Emissions and its Intensity: Limestone} Quarrying (Plant I)

According to raw material utilization, the annual average diesel fuel and grid-electricity consumption of Plant I in 2014 and 2015 were approximately 148,426.97 $\mathrm{L} / \mathrm{yr}$ and $461,066.50 \mathrm{kWh} / \mathrm{yr}$, respectively. Besides, approximately $113,454.48 \mathrm{kgANFO}$ was utilized as blasting agent in the mining process. On the average, limestone rock of Plant I was produced annually $525,024.56$ tonnes per year.

Considering all potential sources of emissions, the total amount of GHGs emitted from limestone mining operations (Plant I) were approximately 1,457.61 $\mathrm{tCO}_{2}$-eq and 1,753.73 $\mathrm{tCO}_{2}$-eq in 2014 and 2015, respectively. As depicted in Fig. 4, combustion of diesel fuel related to transport activities in the mining released almost half (45$58 \%$ ) of total emissions, compared to electricity (33-39\%) and blasting agent utilization (9-16\%), respectively.

In terms of GHGs intensity, the results of calculations were ranged between 18.83-22.36 $\mathrm{kgCO}_{2}$-eq/ton products. It must be noted that, emissions intensity from transport activities associated with diesel fuel consumption was by far the largest share (Fig. 5).

Net GHGs Emissions and its Intensity: Basalt Quarrying (Plant II)

From 2014 to 2015, the average annual basalt rock product of the mining factory (Plant II) was 582,480.50 tons/yr. In the meanwhile, the utilization of diesel fuel and blasting agent was 307,366 L/yr and 52,188.50 kgANFO per year, respectively. As a consequence, the total volume of GHGs emissions from basalt mining operation was $1,670.18 \mathrm{tCO}_{2}$-eq and 1,467.27 $\mathrm{tCO}_{2}$-eq in 2014 and 2015, respectively. The major source of these emissions was diesel combustion, contributing more than $51-57 \%$ of total emissions. Grid-electricity consumption was by far the second largest (35-41\%), followed by blasting agent utilization (8\%), respectively (Fig. 6).

In comparison, the estimated GHG emissions from both limestone and basalt rock mining operations in this study were very low compared to other sources of emissions. For instance, ONEP (2011) reported that the net GHGs emissions in Thailand from energy, transport and residential sectors were approximately 66.4, 44.7, and $6.5 \mathrm{MtCO}_{2} \mathrm{e}$, respectively. Among the industrial sectors, chemical and metal production released 0.3 and $0.01 \mathrm{MtCO}_{2} \mathrm{e}$ of GHGs emissions to the atmosphere. Kanchanapiya et al. (2015), additionally, found that the total GHGs emissions from upstream petrochemical of Thailand equaled about 7-9 $\mathrm{MtCO}_{2} \mathrm{e}$.
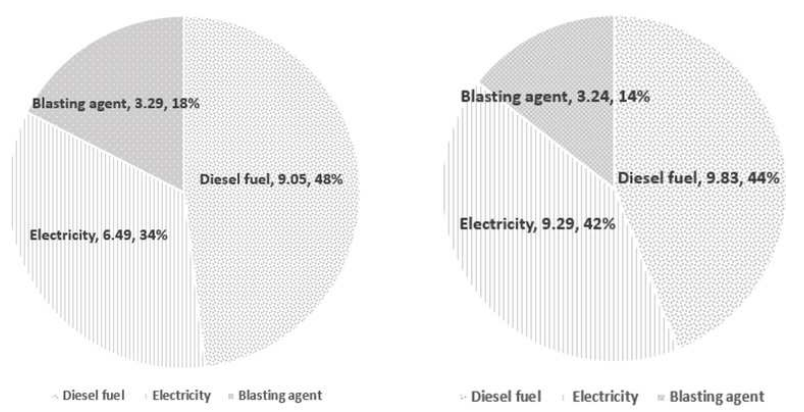

Fig. 5. Proportion of GHGs intensity $\left(\mathrm{kgCO}_{2}\right.$-eq/tonne product), 2014-2015
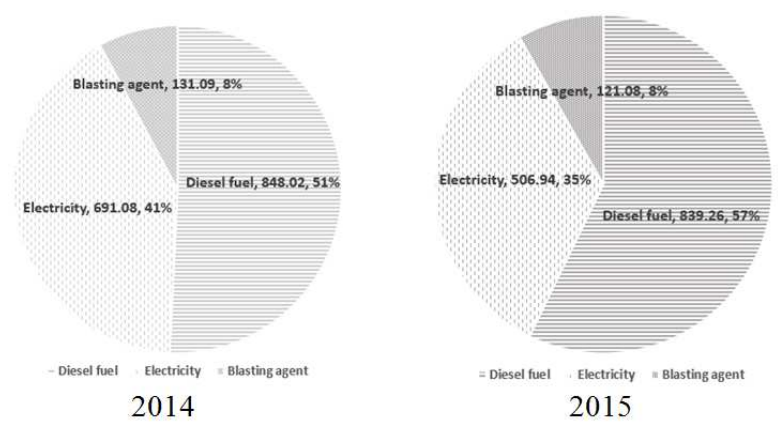

Fig. 6. Proportion of GHGs emissions $\left(\mathrm{tCO}_{2}\right.$-eq) from the basalt rock mining, 2014-2015

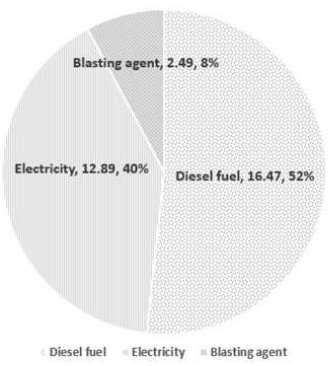

2014

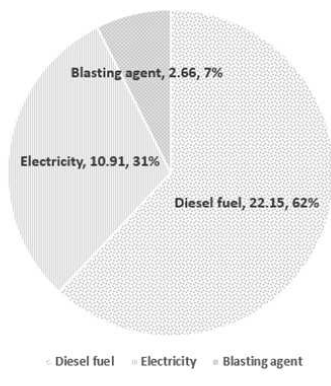

2015
Fig. 7. Proportion of GHGs intensity $\left(\mathrm{kgCO}_{2}\right.$-eq/tonne product) of the limestone and basalt mining operations over 2014-2015

The intensity of GHGs emissions was estimated to range from 31.85 to $35.72 \mathrm{kgCO}_{2}$-eq/tonne products. Mobile emissions (i.e. transport-related activities) were also the biggest source, as can be seen in Fig. 7 and 8.

Comparatively, the results of this study found that annual estimated GHGs emissions from both limestone and basalt rock mining operation (Plant I and Plant II) remained approximately almost the same over 2014 to 2015. It is, however, interesting to observe that average $\mathrm{CO}_{2}$ emissions from both purchased grid-electricity and diesel fuel consumption in the basalt mining process were slightly higher than those from limestone quarrying. 


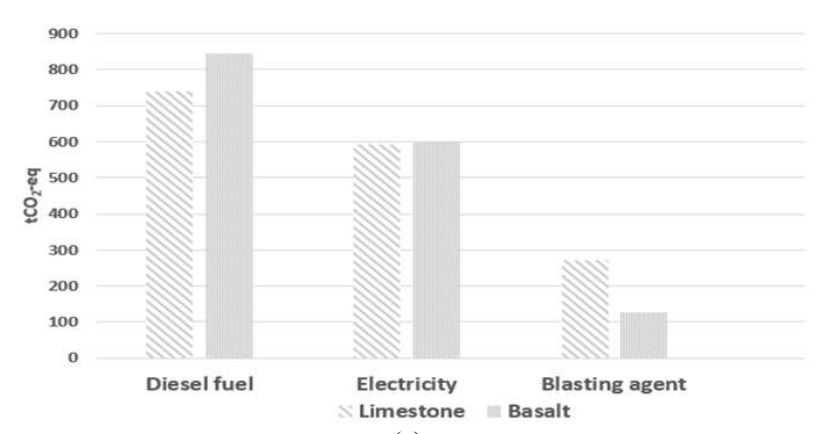

(a)

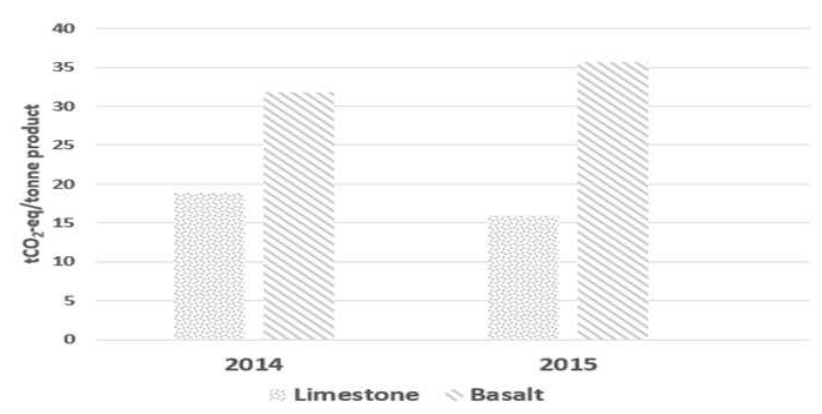

(b)

Fig. 8. Proportion of GHGs emissions (a) and its GHGs intensity (b) 2014-2015

Also, GHGs emissions from the basalt blasting operations were much larger than the utilization of blasting agent in the limestone rock mining. The possible reason might be due to its hardness- an important parameter which characterizes the strength properties of an aggregate. According to the Mohs (US Department of Transportation, 1991), the hardness of limestone is about 3-4 while that hardness scale of basalt is 6 , then the more energy is needed for basalt rock blasting. Recognizing this, within scope 1 , emissions were particularly large from the combustion of diesel fuel in mobile sources for both the limestone and basalt quarrying operations.

Along the same lines with these findings, Environmental Management Office, Department of Primary Industries and Mines and Faculty of Engineering, Chiangmai University of Thailand (2010), reported that the combustion of diesel fuel by mobile mining equipment (i.e. haul trucks) was considered the dominant source of emissions (35\%) rather than the other sources. Ercelebi and Bascetin (2009); Norgate and Haque (2010) and Dindarloo et al. (2015) also found that transport activities were responsible for the majortiy (50$80 \%$ ) of the total $\mathrm{CO}_{2}$ emissions in surface and open-pit mining. In contrast, however, some studies have reported that electricity consumption in crushing and grinding processes were found to be the largest source of GHGs emissions from the coal and metal mining industry (Sterling, 2009; Warmuzinski, 2008; Carras et al., 2009) In gold mining, for example, Kittipongvises (2015) indicated that comminution (i.e. crushing and grinding) process releases the highest GHGs emissions, whereas the electrostatic separation process emits the lowest emissions per annual gold production capacity. In a sense, the authors observed that the patterns of GHGs emissions of the mining industry depend mainly on each type of mineral production process.

Evidently, it has been clearly seen in this study that the combustion of diesel fuel related to transport activities represented the largest source of emissions in both the limestone and basalt rock mining. Potentially, some available mitigation options and practices for reducing these emissions (Delgado and Muncrief, 2015; Kecojevic and Komljenovic, 2010) are considered under below:

- Alternative fuel vehicle and engine: Switching to less carbon-intensive fuel could reduce $\mathrm{CO}_{2}$ emission to the atmosphere and contribute to climate change. This, in turn, Delgado and Muncrief (2015) found that the estimated from diesel-powered vehicles and natural gas-fuel were 2,420 and 2,150 $\mathrm{gCO}_{2}$ per mile, respectively

- Road speed reduction: As reported by the International Council on Clean Transportation (2009), reducing maximum speed from 70 miles per hour (MPH) to $55 \mathrm{MPH}$ could deliver fuel savings by $7.3 \%$ to $8.1 \%$

- Haul truck payload management: Diesel fuel consumption for haul trucks is basically determined based mainly on the gross vehicle weight and haul truck payload. Evidently, Kecojevic, and Komljenovic (2010) reported that a reduction in load factor of $10-30 \%$ can significantly decrease the amount of fuel consumption and also $\mathrm{CO}_{2}$ emissions. For instance, estimated GHGs emissions from haul trucks (Cat 770) in mining ranged from 0.0547 to 0.1367 ton $/ \mathrm{hr}$ for load factors of $20 \%$ and $50 \%$, respectively

\section{Conclusion}

The mining industry has the opportunity to positively contribute to the Sustainable Development Goals (SDGs) or the world's plan of action. In terms of environmental sustainability, mineral processing causes negative impacts on water, land, energy, and people that depend on these finite resources. To tackle major global challenges like climate change and also promote the Thailand's green mining policy, the purposes of this present study were to investigate all potential sources of GHGs and also estimate their total emissions from both limestone and basalt mining operations in Thailand. Reducing energy consumption at mines can reduce GHGs emissions. Accordingly, there were three potential sources of emission: (i) diesel fuel consumption (direct emission), (ii) blasting agent (direct emission) and (iii) purchased grid-electricity utilization (indirect emission). 
Results showed that the total GHGs emissions from the limestone and basalt rock quarrying operations, in 2014 and 2015, were almost the same. Interestingly, the amount of diesel fuel and electricity consumed by the basalt mining plant were generally higher than those from the limestone rock quarrying operations. Rock hardness may be an important factor influencing both fuel consumption and GHGs emissions. Furthermore, compared to the other sources, $\mathrm{CO}_{2}$ emissions from the limestone and basalt mining were directly proportional to the combustion of fuel related to transport activities (i.e. haul trucks). GHGs reduction from transportation sources in the mining industry offers a high potential for mitigating climate change. However, in light of the above consideration, lack of proper tool that can be applied to assess the complete range of environmental problems (i.e. risk analysis, cost-benefit analysis, etc.) (Niyomthai and Wattanawan, 2014) and also lack of available activity data that can be used to estimate the GHGs emissions are one of the key challenges ahead for the implementation of the green mining policy in Thailand.

\section{Acknowledgement}

The authors thank the Office of Higher Education Commission (OHEC) and the S\&T Postgraduate Education and Research Development Office (PERDO) for the financial support of the Research Program and thank the Ratchadaphiseksomphot Endowment Fund, Chulalongkorn University for the Research Unit. We would like to express our sincere thanks to the Environmental Research Institute (ERIC) and the Center of Excellence on Hazardous Substance Management (HSM) Chulalongkorn University for their invaluable supports in terms of facilities and scientific equipment.

\section{Author's Contributions}

Dubsok Atima: Designed and wrote the manuscript.

Kittipongvises Suthirat: Wrote, conceived and revised the manuscript.

\section{Ethics}

The authors declare no conflict of interest.

\section{References}

Delgado, O. and Muncrief, R., 2015. Assessment of heavy-Duty natural gas vehicle emissions: implications and policy recommendations. International Council on Clean Transportation, Washington, DC, USA.

DPIM, 2016. Industrial rock-construction data source.

Dindarloo, S.R., M. Osanloo and S. Frimpong, 2015. A stochastic simulation framework for truck and shovel selection and sizing in open pit mines. J. Southern African Institute Mining Metallurgy, 115: 209-219. DOI: 10.17159/2411-9717/2015/v115n3a6
Dubiński, J., 2013. Sustainable development of mining mineral resources. J. Sustainable Mining, 12: 1-6. DOI: $10.7424 /$ jsm 130102

Environmental Management Office, Department of Primary Industries and Mines and Faculty of Engineering, Chiangmai University, 2010. Reporting guidelines for development of mining industry to Clean Development Mechanism (CDM). Ministry of Industry, Bangkok, Thailand.

Ercelebi, S. and G. Bascetin, 2009. A. Optimizing of shovel-truck system for surface mining. J. Southern African Institute Mining Metallurgy, 109: 433-439.

Gao, T., Q. Liu and J. Wang, 2013. A comparative study of carbon footprint and assessment standards. Int. J. Low-Carbon Technologies Advance Access, 0: 1-7.

International Council on Clean Transportation, 2009. Reducing heavy-duty long haul combination truck fuel consumption and $\mathrm{CO}_{2}$ emissions. Washington, DC, USA.

IPCC, 2013. Climate Change 2013: IPCC Fifth Assessment Report. Geneva, Switzerland.

Carras, J.N., S.J. Day, A. Saghafi and D.J. Williams, 2009. Greenhouse gas emissions from lowtemperature oxidation and spontaneous combustion at open-cut coal mines in Australia. Int. J. Coal Geology, 78: 161-168.

DOI: 10.1016/j.coal.2008.12.001

Kanchanapiya, R., N. Julapun, N. Limphitakphong, C. Pharino and O. Chavanparit, 2015. Evaluation of emission and reduction of greenhouse gases from upstream petrochemical industry in Thailand. Environment Protection Engineering, 41: 31-46.

Kecojevic, V. and D. Komljenovic, 2010. Haul truck fuel consumption and $\mathrm{CO}_{2}$ emission under various engine load conditions. Mining Engineering Magazine, 13: 44-48.

Kittipongvises, S., 2015. Feasibility of applying clean development mechanism (CDM) and GHGs emissions reductions in the Gold mining industry: A case of Thailand. Environmental and Climate Technologies, 15(1): 34-47.

DOI: $10.1515 /$ rtuect-2015-0004

Mudd, M.G. and M. Diesendorf, 2008. Sustainability of Uranium mining and milling: Towards quantifying resources and eco-efficiency. Environ. Science Technology, 42: 2624-2630. DOI: $10.1021 / \mathrm{es} 702249 \mathrm{v}$

Mudd, M.G. 2007. Global trends in gold mining: towards quantifying environmental and resource sustainability? Resources Policy, 32(1-2): 42-56. DOI: 10.1016/j.resourpol.2007.05.002

Mudd, M.G. 2010. The Environmental sustainability of mining in Australia: key mega-trend and looming contraints. Resources Policy, 35: 98-115. DOI: 10.1016/j.resourpol.2009.12.001 
Niyomthai, S. and A. Wattanawan, 2014. Sustainable mining in Thailand: Paradigm shift in environmental management. Applied Environmental Research, 36: 55-63.

Norgate, T. and N. Haque, 2010. Energy and greenhouse gas impacts of mining and mineral processing operations. J. Cleaner Production, 18: 266-274. DOI: 10.1016/j.jclepro.2009.09.020

Office of the National Economic and Social Development Board (NESDB), 2015. Climate Change. Pomprab, Bangkok, Thailand.

ONEP, 2011. United Nations Framework Convention on Climate Change. Phayathai, Bangkok, Thailand.

Sterling, D., 2009. Identifying opportunities to reduce the consumption of energy across mining and processing plants. Schneider-Electric.

Thailand Greenhouse Gas Management Organization (TGO), 2015. Emission Factor by Industrial Sectors. Laksi, Bangkok, Thailand.

Thailand Greenhouse Gas Management Organization (TGO), 2012. Thailand Industrial Sector GHG Emission. Laksi, Bangkok, Thailand.
United Nations (UN), 2014. The millennium development goals report, New York.

United State Environmental Protection Agency (US EPA), 1995. Explosives Detonation. Washington, DC, USA.

United State Environmental Protection Agency, 2014. Global Greenhouse Gas Emissions Data. Washington, DC, USA.

US Department of Transportation, 1991. Rock and Mineral Identification for Engineers. Federal Highway Administration.

Warmuzinski, K., 2008. Harnessing methane emissions from coal mining. Process Safety Environmental Protection, 86: 315-320.

DOI: 10.1016/j.psep.2008.04.003

WRI, 2011. The greenhouse gas protocol: A corporate accounting and reporting standard (Revised Edition). World Business Council for Sustainable Development, Geneva, Switzerland. 